\title{
Constrained Finite Strip Method with Rigid Corner Element for the Buckling Analysis of Thin-Walled Members with Rounded Corners
}

\author{
Zoltán Beregszászi, Sándor Ádány \\ ${ }^{1}$ Department of Structural Mechanics, \\ Faculty of Civil Engineering, \\ Budapest University of Technology and Economics, \\ H-1521 Budapest, P.O.B. 91, Hungary \\ *Corresponding author, e-mail: zbereg@hu.inter.net
}

Received: 06 August 2018, Accepted: 14 November 2018, Published online: 16 January 2019

\begin{abstract}
In this paper modal decomposition of the deformations of thin-walled structural members are discussed. Modal decomposition is a process which separates the characteristic behavior modes. If applied in buckling analysis, modal decomposition makes it possible to analyze pure global or pure distortional buckling or pure local-plate buckling. Ability to calculate critical loads to a pure buckling mode is highly useful in the design of thin-walled structural members, such as cold-formed steel beams or columns. Cold-formed steel profiles are always produced with rounded corners, and earlier studies showed that the now-used modal decomposition techniques of the constrained finite element method and generalized beam theory fail to lead to reasonable results if the rounded corners are directly modelled in the analysis. An extension to the constrained finite strip method is proposed and discussed. The proposal introduces rigid corner elements, which make it possible to perform the modal decomposition by the same process used for members with sharp corners, even if the rounded corners are directly modelled. The formulation of the proposal is summarized, then the rigidcorner approach is studied by an extended parametric study.
\end{abstract}

Keywords

buckling, rounded corner, modal decomposition, thin-walled member, corner modelling

\section{Introduction}

A widely used engineering approach to complex problems is to interpret the complex problem as a combination of simpler ones, since the simpler problems are typically easier to understood, can be described by fewer parameters, and there is better chance to find practically usable mathematical models to describe them. In accordance with this engineering attitude, it is common to interpret the behavior of a thin-walled structural member as the superposition of global (G), distortional (D), local (L) and other (O) deformation modes, which last $\mathrm{O}$ class is sometimes further subdivided into shear (S) and transverse extension (T) modes. If the beam or column member is subjected to (axial) compressive stresses, buckling is crucially important, hence, it is usual to distinguish global buckling (e.g., flexural buckling or flexural-torsional buckling of columns, or lateral-torsional buckling of beams), distortional buckling or local buckling (e.g., plate buckling, shear buckling, etc.) The specific deformation or buckling modes can be studied via the modal decomposition.

The underlying mathematical procedure of modal decomposition is a transformation of base system. Today discretization methods are widely used, where the transformation of the base system practically means that modal degrees of freedom are employed instead of the classical nodal degrees of freedom. This transformation has various potential advantages. It makes possible to significantly reduce the number of degrees of freedom (DOF) in a general (e.g., first- or second-order static) analysis. It also makes possible to perform an analysis for a specific deformation class, e.g., to have buckling solution specifically for global or local-plate modes. Moreover, base system transformation makes possible to perform modal identification, i.e., to assign participation percentages from the mode types to any general deformation mode. 
Today there are essentially two numerical techniques with modal decomposition abilities for thin-walled members. One is the generalized beam theory (GBT), see e.g. [1-3], which is evolved from a classic thin-walled beam theory to a numerical method which can solve practically the same problems that can be solved by a shell finite element calculation. The other technique is a constraining technique that applied first to the semi-analytical finite strip method (FSM), leading to the so-called constrained finite strip method (cFSM), see e.g., [4-9], then more recently extended to shell finite element method, leading to the so-called constrained finite element method (cFEM), see [10-13]. It is a common feature of both alternative techniques that the modal decomposition is problematic if the member model includes narrow, nearly parallel flat parts (e.g., strips), which might be the case if rounded corners or small stiffeners are directly modelled by approximating them with multiple narrow strips. The problem is that though the base system transformation can technically be completed even in these cases, the distinction of local(-plate) and distortional deformation modes fails to comply with the engineering expectations. The case of rounded corners is especially pronounced in the practice, since cold-formed steel members, which are one of the most typical structural engineering applications of thin-walled structural members, are always produced with rounded corners due to technological reasons.

The problem of modal decomposition in members with rounded corners has been identified in [14-15]. In [1619] some practical solutions have also been proposed for how to utilize the advantages of modal decomposition in the buckling design of members with rounded corners. However, in these proposals the modal decomposition is completed on sharp-corner member models only. Later, in [20-21] two approaches have been introduced for the real modal decomposition of rounded-corner members by using special versions of cFSM: though some proof-ofconcept examples are presented, no detailed studies have been presented. In this current paper the in-depth analysis of the so-called rigid-corner approach is provided.

\section{Problem statement}

\subsection{FSM and cFSM}

The finite strip method (FSM) is a shell-model-based discretization method [22-23]. By utilizing longitudinal regularity, a common characteristic in thin-walled members, FSM requires a significantly smaller number of degrees of freedom (DOF) than the shell finite element method (FEM).

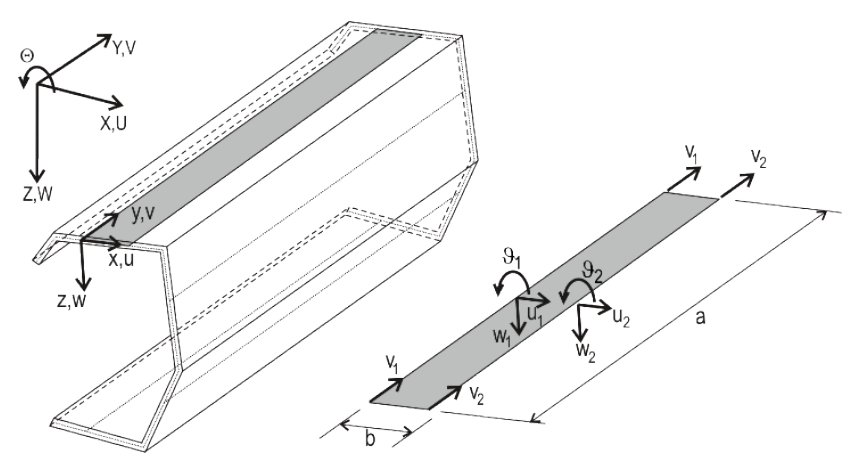

Fig. 1 Finite strip discretization, degrees of freedom

Members are discretized into longitudinal strips as shown in Fig. 1. Note, Fig. 1 illustrates the nodal displacements for the simplest longitudinal shape functions, as given in Eqs. (1-5), with $m=1$.

Within a strip, local in-plane $(u, v)$ and out-of-plane (w) displacement functions are expressed as the product of longitudinal and transverse shape functions. The longitudinal shape functions are trigonometric functions, while the transverse shape functions are classic linear or cubic polynomial functions. With using the simplest longitudinal trigonometric functions, the displacements are approximated as follows.

$u(x, y)=\left[\begin{array}{ll}N_{1}^{(1)} & N_{2}^{(1)}\end{array}\right]\left[\begin{array}{l}u_{1} \\ u_{2}\end{array}\right] \sin \frac{m \pi y}{a}$
$v(x, y)=\left[\begin{array}{ll}N_{1}^{(1)} & N_{2}^{(1)}\end{array}\right]\left[\begin{array}{l}v_{1} \\ v_{2}\end{array}\right] \cos \frac{m \pi y}{a}$

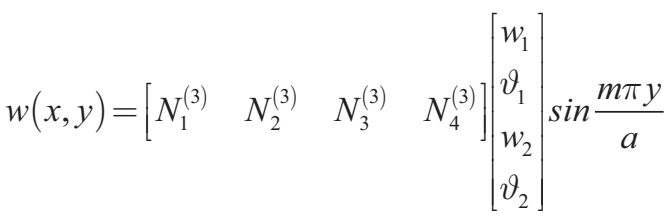

with

$N_{1}^{(1)}=1-\frac{x}{b} \quad N_{2}^{(1)}=\frac{x}{b}$

and

$$
\begin{aligned}
& N_{1}^{(3)}=1-\frac{3 x^{2}}{b^{2}}+\frac{2 x^{3}}{b^{3}} \quad N_{2}^{(3)}=-x+\frac{2 x^{2}}{b}-\frac{x^{3}}{b^{2}} \\
& N_{3}^{(3)}=\frac{3 x^{2}}{b^{2}}-\frac{2 x^{3}}{b^{3}} \quad N_{4}^{(3)}=\frac{x^{2}}{b}-\frac{x^{3}}{b^{2}}
\end{aligned}
$$

where $a$ is the member length, and $b$ is the strip width. The above formulae represent locally and globally pinned boundary conditions at both member ends. Other end 
restraints can also be handled, but the longitudinal trigonometric shape functions must by changed accordingly. For more general restraints, function series are necessary.

By using the above interpolations various classical engineering problems can readily be handled, including first- or second-order static analysis, vibration analysis, etc. However, the most popular application of the method (in case of thin-walled cold-formed members) is the linear buckling analysis, as in CUFSM software [24]. The calculation of buckling loads and corresponding buckled shapes require the solution of an eigen-value problem as follows:

$\mathrm{K}_{\mathrm{e}} \Phi-\Lambda \mathrm{K}_{\mathrm{g}} \Phi=\mathbf{0}$

where $\mathbf{K}_{\mathbf{e}}$ and $\mathbf{K}_{\mathrm{g}}$ are the elastic and geometric stiffness matrices, respectively, the size of which is $4 n$ by $4 n$, where $n$ is the number of nodal lines. The stiffness matrices can be compiled from the elementary stiffness matrices of the strips, as usual in finite element or finite strip method. The solution of the eigen-value problem leads to

$$
\begin{aligned}
& \Lambda=\operatorname{diag}\left[\begin{array}{lllll}
\lambda_{1} & \lambda_{2} & \lambda_{3} & \ldots & \lambda_{4 n}
\end{array}\right] \\
& \Phi=\left[\begin{array}{lllll}
\Phi_{1} & \Phi_{2} & \Phi_{3} & \ldots & \Phi_{4 n}
\end{array}\right]
\end{aligned}
$$

where $\lambda_{i}$ is the critical load multiplier and $\phi_{i}$ is the mode shape vector $(i=1 \ldots 4 \times n)$. It is to note that most usually the necessary DOF number is fairly small, and the stiffness matrices have block diagonal structure, which makes the FSM calculation extremely time-efficient.

The constrained FSM (cFSM) is an extension to FSM that uses equations to enforce or classify deformations to be consistent with a desired set of mechanical criteria. The cFSM constraints are inspired by structural engineering practice, in which it is useful to be able to formally categorize deformations into deformation classes such as global, distortional, local, or other. Specifically, any FSM displacement field $\mathbf{d}$, including an eigen-buckling mode $\phi_{i}$, may be constrained to any deformation space (or mode space) M via:

$\mathbf{d}=\mathbf{R}_{\mathrm{M}} \mathbf{d}_{\mathrm{M}}$

where $\mathbf{R}_{\mathrm{M}}$ is a constraint matrix, and $\mathrm{M}$ might be, e.g., $\mathrm{G}$, D, L, etc., or any sub-classes of G, D, L, etc..

Modal decomposition of the eigen-buckling solution is completed by applying the $\mathbf{R}_{\mathrm{M}}$ constraint matrix for the given $\mathrm{M}$ space, the columns of which can be interpreted as base vectors for the given space. Introducing Eq. (9) to Eq. (6), we get a constrained eigen-value problem:

$\mathbf{R}_{\mathrm{M}}{ }^{\mathrm{T}} \mathbf{K}_{\mathrm{e}} \mathbf{R}_{\mathrm{M}} \boldsymbol{\Phi}_{\mathrm{M}}-\Lambda_{\mathrm{M}} \mathbf{R}_{\mathrm{M}}{ }^{\mathrm{T}} \mathbf{K}_{\mathrm{g}} \mathbf{R}_{\mathrm{M}} \boldsymbol{\Phi}_{\mathrm{M}}=\mathbf{0}$
$\mathbf{K}_{\mathrm{eM}} \boldsymbol{\Phi}_{\mathrm{M}}-\boldsymbol{\Lambda}_{\mathrm{M}} \mathbf{K}_{\mathrm{gM}} \boldsymbol{\Phi}_{\mathrm{M}}=\mathbf{0}$

where $\mathbf{K}_{\mathrm{eM}}$ and $\mathbf{K}_{\mathrm{gM}}$ are reduced-size elastic and geometric stiffness matrices for the eigen-buckling solution constrained to space $\mathrm{M}$.

The modal decomposition in cFSM is based on simple mechanical criteria, summarized in Table 1. It is to note that some further criteria are practically necessary to have the constraint matrices, e.g., to enforce orthogonality between certain deformation spaces. These questions are discussed in detail in earlier publications [2-4]. It is also to mention that more refined version of the mechanical criteria of Table 1 has already been proposed [8-9], which is necessary in case of general cross-sections (e.g., cross-sections with closed parts).

Since the aim of this actual paper is to discuss the effect of rounded corners, and since rounded corners are the characteristic features of cold-formed steel members, which are mostly open sections, here it is enough to consider the original, simpler mode definition table, as in Table 1.

\subsection{Illustration of the problem of rounded corners in modal decomposition}

A typical appearance of thin-walled members is coldformed steel, when the members are bended from thin flat sheets. A very basic characteristic of cold-forming process is that the corners of the final products are rounded. When such a member is modelled and analyzed by FSM, a reasonable approach is to use multiple (very) narrow strips for the corner area in order to smoothly approximate the real geometry of the member. While this way of directly considering the rounded corners leads to accurate results in case of an unconstrained FSM analysis (i.e., first- or second-order analysis, or linear buckling analysis), it causes trouble in constrained FSM.

The problem of rounded corners is illustrated by some numerical examples. Pinned-pinned column members with a C-shaped cross-sections subjected to uniform compression are studied. Three cases are mentioned here, in each case the cross-section is: $160-60-15$, (i.e., web depth is 160 $\mathrm{mm}$, flange width is $60 \mathrm{~mm}$, and lip length is $15 \mathrm{~mm}$,) but

Table 1 Mechanical criteria for mode classes in cFSM

\begin{tabular}{lcccc}
\hline mechanical criteria & $\mathrm{G}$ & $\mathrm{D}$ & $\mathrm{L}$ & $\mathrm{S} / \mathrm{T}$ \\
\hline$\varepsilon_{x}=\partial u / \partial x=\& \gamma_{x y}=\partial u / \partial y+\partial v / \partial x=0$ & Yes & Yes & Yes & No \\
$v \neq 0 \&$ transverse equilibrium & Yes & Yes & No & - \\
$\kappa_{x}=\partial^{2} w / \partial x^{2}=0$ & Yes & No & - & - \\
\hline
\end{tabular}


the thickness and the corner radius is varying. In the first case the corner radius is $2 \mathrm{~mm}$, the thickness is $1.0 \mathrm{~mm}$ (therefore, the case is marked as: 160-60-15-2-1.0), in the second case the corner radius is $4 \mathrm{~mm}$, the thickness is 1.5 mm (marked: 160-60-15-4-1.5), while in the third case the corner radius is $6 \mathrm{~mm}$, the thickness is $2.0 \mathrm{~mm}$ (marked: 160-60-15-6-2.0). The middle case represents a typical practical case, while the first and third case an unusually small or unusually large corner radius, respectively. The problems are solved in various options, calculating the lowest critical stress. The options are: with and without considering the rounded corners, and with applying various modal constraints: pure G, pure D, and pure L critical load values are obtained by enforcing G, D or L deformation modes, respectively, while all-mode critical load value is calculated by using all the modes. This latter all-mode solution, therefore, is equivalent with the unconstrained solution (i.e., when modal constraint are not enforced).

In Fig. 2 the critical stress are plotted against the buckling length, where buckling length is interpreted as the length of the characteristic half-wave length of the buckled shape. (This type of plot is also referred as to signature curve of the cross-section.) It is to note that for the assumed shape functions with $m=1$, see Eqs. (1)-(3) the buckling length is equal to the member length, hence the terms "length", "buckling length" and "member length" will be used hereafter as synonyms. In the figure the 160-60-15-41.5 problem is shown: all-mode (i.e., unconstrained) solutions for sharp-corner and rounded-corned models, as well as the pure-mode solutions for the sharp-corner cases. As it is well-known, and also obvious from the figures, for short lengths the local buckling governs, for long lengths global buckling governs (in this case: flexural and/or flexural-torsional buckling), while for intermediate lengths distortional buckling governs. It is also observable that the direct consideration of rounded corners does not mean any significant change in the critical values, independently of the buckling length. Finally, the figure also illustrate the common knowledge (and engineering expectation) that pure mode critical values are typically larger, but only slightly larger than all-mode critical values, where "slightly larger" means a maximum few percentage for $\mathrm{L}$ and $\mathrm{G}$ cases, while $10-30 \%$ for D cases. (It is to note that the calculation is performed with zero Poisson's ratio, in order to avoid the artificial increased stiffness of $G$ and $\mathrm{D}$ modes due to restrained transverse contraction, as discussed in [25-26].)

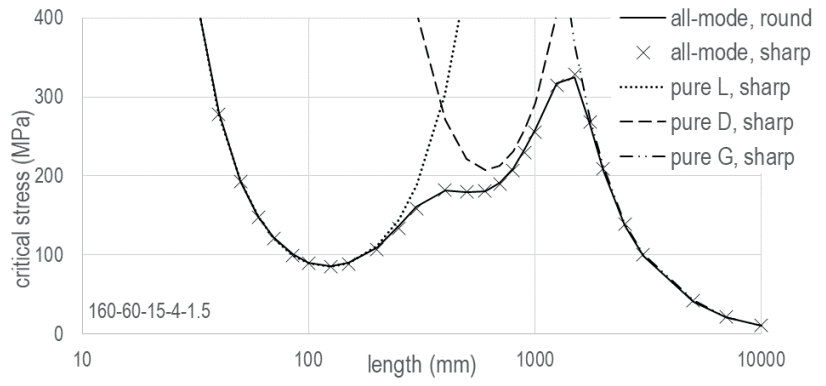

Fig. 2 Typical signature curves.

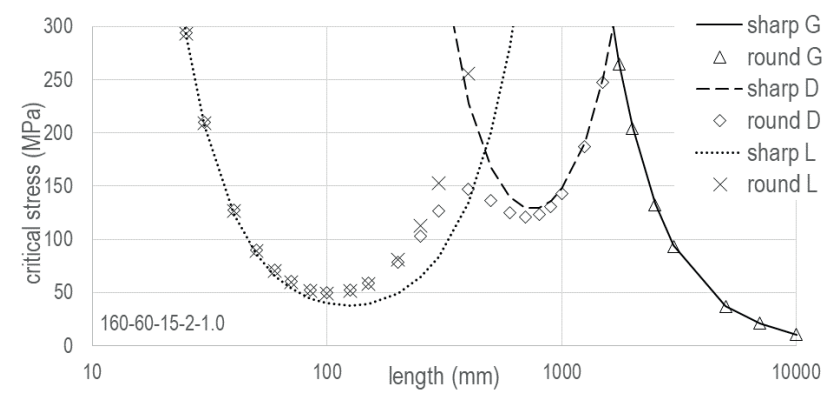

Fig. 3 Pure mode solutions for sharp and rounded models, member 160-60-15-2-1.0.

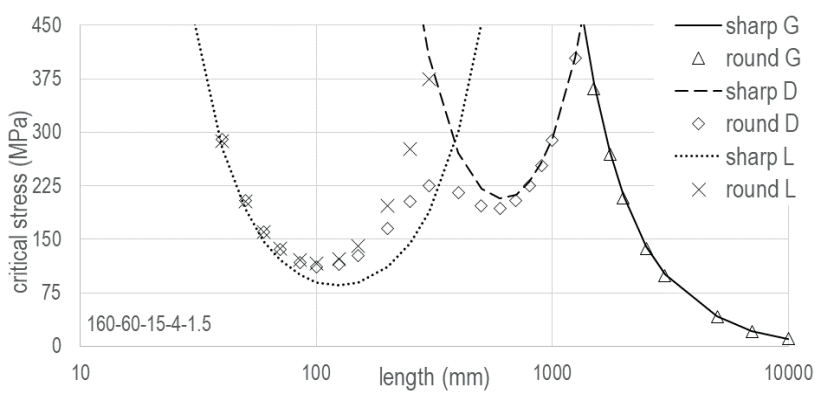

Fig. 4 Pure mode solutions for sharp and rounded models, member 160-60-15-4-1.5.

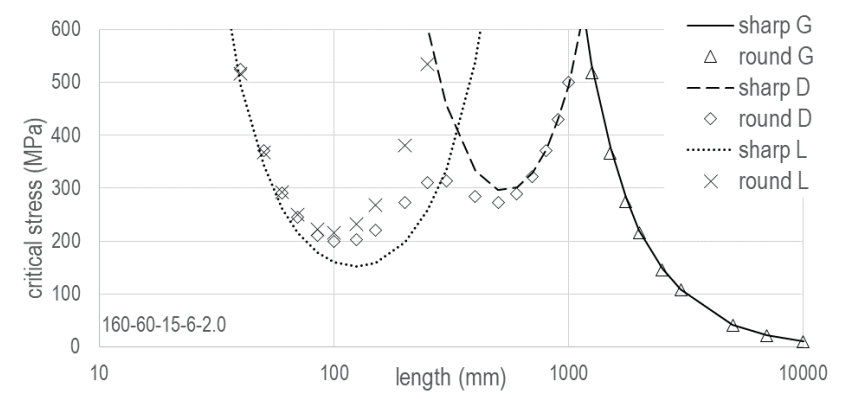

Fig. 5 Pure mode solutions for sharp and rounded models, member 160-60-15-6-2.0.

If pure-mode curves are calculated for rounded-corner models by simply following the cFSM procedure (as summarized in Section 2.1), the solutions fail to comply with the engineering expectations. Pure-mode solutions are shown in Figures 3-5, both with sharp-corner and rounded-corner models. While G solutions show the expected tendency, L and D solutions have shown strange 
tendencies. One strange phenomenon is that pure L critical values of rounded-corner models are too large w.r.t. their sharp-corner counterparts. Another strangeness is that the pure $\mathrm{D}$ curve has two minimums: one in the $\mathrm{L}$ region (where it is not expected), another one in the $\mathrm{D}$ region (where it is expected), but even in this latter case the calculated minimal D critical stress with the rounded corners is unexpectedly lower compared to the similar D critical stress with the sharp corners. As the figures prove, the above phenomena are essentially independent of the actual corner geometry; it exists when the corner radius is unusually small or large.

In Tables 2-4 some critical stress values are also compared for selected buckling lengths. Three lengths are selected from the L region: one very small one (i.e., 10 $\mathrm{mm}$ ), a second one at the L minimum, and a third one which is the largest length where $\mathrm{L}$ is the governing buckling type. Three lengths are selected from the D region, too: the first one is the smallest length where D type governs, the second one belongs to the $\mathrm{D}$ minimum, while the third one is the largest length where D governs. Finally, three lengths are selected for $\mathrm{G}$ modes, too: the first one is the smallest length where $\mathrm{G}$ governs. The third one is a very large length (10 $000 \mathrm{~mm}$ in our cases), while the second one is a moderately large length where $G$ governs. It is to understand that most of these lengths are dependent on the actual problem (i.e., geometry, loading). It is also to note that from practical point of view the second $\mathrm{L}$ and second $\mathrm{D}$ length are the most important ones out of the $\mathrm{L}$ and $\mathrm{D}$ lengths, respectively.

The numerical values of the critical loads prove that there is little difference between the sharp-corner and rounded-corner models if modal constraints are not applied, independently of the length. This is also true for the $\mathrm{G}$ region even if pure-mode solutions are calculated. However, pure-mode critical stresses in the L and $D$ regions seem to be incorrect whenever the rounded corners are directly modelled. For example: the difference between sharp and rounded corner critical values at the D minimum is $1-3 \%$ in all-mode calculations, but as large as $10-20 \%$ in pure-mode calculations. Or, the difference between all-mode and pure-mode calculations at the $\mathrm{L}$ minimum is less than $1 \%$ if the corners are sharp, but can be as large as $30-50 \%$ if the corners are rounded.

The problem is visible from the buckled shapes. In Fig. 6 possible pure-L buckled shapes are shown for a $\mathrm{C}$-section with a relatively large corner radius. In Fig. 6a) the wellknown deformed cross-section is shown for the (lowest)
Table 2 Comparison of critical stresses calculated in various options, $160-60-15-2-1.0$

\begin{tabular}{lccccc}
\hline Mode & length & $\begin{array}{c}\text { sharp } \\
\text { corner } \\
\text { class }\end{array}$ & $\begin{array}{c}\text { rounded } \\
\text { corner } \\
\text { all mode }\end{array}$ & $\begin{array}{c}\text { sharp } \\
\text { corner } \\
\text { all mode }\end{array}$ & $\begin{array}{c}\text { rounded } \\
\text { corner }\end{array}$ \\
\cline { 3 - 6 } & $(\mathrm{mm})$ & $(\mathrm{MPa})$ & $(\mathrm{MPa})$ & $(\mathrm{MPa})$ & $(\mathrm{MPa})$ \\
\hline $\mathrm{L}$ & 10 & 1741 & 1741 & 1741 & 1743 \\
L & 125 & 37.79 & 38.03 & 37.87 & 51.54 \\
L & 400 & 105.2 & 105.7 & 134.5 & 255.8 \\
$\mathrm{D}$ & 500 & 114.8 & 114.7 & 167.0 & 136.8 \\
$\mathrm{D}$ & 800 & 115.1 & 115.5 & 129.4 & 123.1 \\
$\mathrm{D}$ & 1500 & 201.7 & 202.7 & 252.0 & 248.0 \\
$\mathrm{G}$ & 1750 & 218.5 & 217.9 & 266.8 & 264.9 \\
G & 3000 & 93.72 & 93.15 & 94.13 & 93.52 \\
G & 10000 & 10.55 & 10.42 & 10.56 & 10.42 \\
\hline
\end{tabular}

Table 3 Comparison of critical stresses calculated in various options, $160-60-15-4-1.5$

\begin{tabular}{lccccc}
\hline Mode & length & $\begin{array}{c}\text { sharp } \\
\text { corner } \\
\text { class }\end{array}$ & $\begin{array}{c}\text { rounded } \\
\text { corner } \\
\text { all mode }\end{array}$ & $\begin{array}{c}\text { sharp } \\
\text { corner }\end{array}$ & $\begin{array}{c}\text { rounded } \\
\text { corner }\end{array}$ \\
\cline { 3 - 6 } & $(\mathrm{mm})$ & $(\mathrm{MPa})$ & $(\mathrm{MPa})$ & $(\mathrm{MPa})$ & $(\mathrm{MPa})$ \\
\hline $\mathrm{L}$ & 10 & 3918 & 3919 & 3918 & 3922 \\
$\mathrm{~L}$ & 125 & 84.79 & 86.26 & 85.20 & 122.9 \\
$\mathrm{~L}$ & 300 & 158.7 & 161.2 & 188.4 & 374.8 \\
$\mathrm{D}$ & 400 & 182.6 & 182.1 & 271.5 & 215.6 \\
$\mathrm{D}$ & 600 & 180.6 & 180.8 & 207.2 & 193.6 \\
$\mathrm{D}$ & 1250 & 315.2 & 317.2 & 404.8 & 404.1 \\
$\mathrm{G}$ & 1500 & 328.5 & 324.7 & 367.4 & 361.6 \\
$\mathrm{G}$ & 3000 & 100.1 & 98.80 & 100.3 & 99.03 \\
$\mathrm{G}$ & 10000 & 10.56 & 10.27 & 10.56 & 10.28 \\
\hline
\end{tabular}

Table 4 Comparison of critical stresses calculated in various options, $160-60-15-6-2.0$

\begin{tabular}{|c|c|c|c|c|c|}
\hline $\begin{array}{l}\text { Mode } \\
\text { class }\end{array}$ & length & $\begin{array}{l}\text { sharp } \\
\text { corner } \\
\text { all mode }\end{array}$ & $\begin{array}{l}\text { rounded } \\
\text { corner } \\
\text { all mode }\end{array}$ & $\begin{array}{c}\text { sharp } \\
\text { corner } \\
\text { pure mode }\end{array}$ & $\begin{array}{c}\text { rounded } \\
\text { corner } \\
\text { pure mode }\end{array}$ \\
\hline & $(\mathrm{mm})$ & $(\mathrm{MPa})$ & $(\mathrm{MPa})$ & $(\mathrm{MPa})$ & $(\mathrm{MPa})$ \\
\hline $\mathrm{L}$ & 10 & 6965 & 6968 & 6965 & 6976 \\
\hline $\mathrm{L}$ & 125 & 150.2 & 155.1 & 151.5 & 232.0 \\
\hline $\mathrm{L}$ & 300 & 249.0 & 251.5 & 335.0 & 727.8 \\
\hline D & 400 & 257.4 & 255.1 & 332.4 & 283.5 \\
\hline $\mathrm{D}$ & 500 & 255.3 & 254.8 & 297.0 & 273.4 \\
\hline D & 1000 & 404.9 & 411.7 & 495.8 & 500.2 \\
\hline $\mathrm{G}$ & 1250 & 446.0 & 440.0 & 532.5 & 518.5 \\
\hline G & 2500 & 147.7 & 144.7 & 148.2 & 145.1 \\
\hline G & 10000 & 10.56 & 10.11 & 10.56 & 10.11 \\
\hline
\end{tabular}


local buckling mode of a C-shaped member, (due to concentric axial compression,) if the member is modelled with sharp corners. If a similar cFSM buckling analysis is performed on a member modelled with rounded corners, the buckled cross-section shape is different, as shown in Fig. $6 \mathrm{~b})$. The buckled shape in accordance with the engineering expectation is presented in part c) of the figure.

The above described phenomenon is a direct consequence of the applied mode definitions. As mentioned earlier: nodal lines at corners (i.e., intersection of two non-parallel strips) can and do displace in D modes, while do not displace in L modes. If the rounded corners are modelled by multiple narrow strips, there are multiple corner nodes at each real corner, the displacement of all of them being prevented in $\mathrm{L}$ modes. That is why the whole corner zones in Fig. 6b) are practically undeformed. On the other hand, small nodal displacements of the nodal lines in the corner zones are necessary in order to get a buckled shape shown in Fig. 6c), i.e., a buckled shape that is expected and desired from practical engineering aspect.

\subsection{Aim, outline}

The aim here is to develop an approach in which the rounded corners are directly modelled, but still, if modal decomposition is applied, the buckling results satisfy the engineering expectations. Two alternatives are worked out: (i) approach with rigid corners and (ii) approach with elastic corner. Both methods have been introduced and presented in scientific conferences [20-21], but in these earlier papers proof-of-concept examples are presented only. In the current paper the in-depth analysis of the rigid-corner approach is provided. First some selected examples are carefully studied. Then, a parametric study is completed: large number of lipped channel column members are considered covering a wide range of possible cross-section geometries, buckling problem is solved with and without considering the rounded corners, and with and without applying modal constraints, then the results are evaluated.

\section{3 cFSM with rigid corner elements 3.1 Summary of the method}

The rigid-corner approach, which is employed here, is developed to eliminate the problem of modal constraints when applied to members with rounded corners. An important aspect in the development of the proposal was to keep the original mode definition criteria (see Table 1), at least for the flat parts of the member, in order to avoid

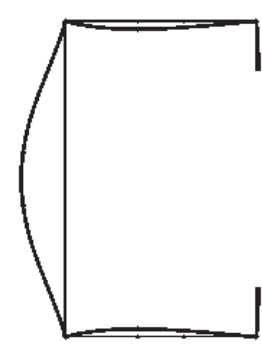

a)

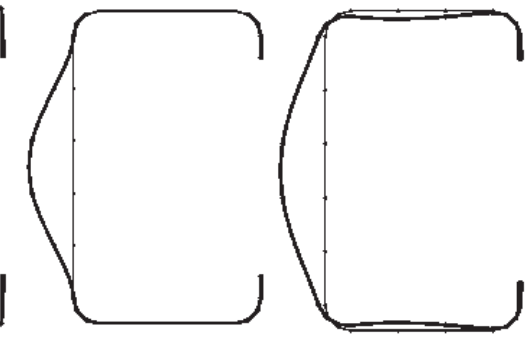

b) c)
Fig. 6 Cross-section deformations for various L buckling modes

discrepancy between the sharp-corner and rounded-corner modal decomposition methods. Since the problem is due to the combination of assumed mechanical criteria and the narrow strips in the corner area, and since the mechanical criteria are intended to keep unchanged, somehow the narrow strips must be eliminated. The elimination of multiple narrow strips can be completed by defining and applying specific constraint for the corner nodes, which process can reduce the original DOF (of the rounded-corner model) to DOF similar (or even identical) to that of a sharp-corner model. Though various such constraining techniques might exist for the corners (see e.g. [21]), here the simplest is used: corner nodes are assumed to be rigidly connected to the (theoretical) corner point. In other words, the strips in the curved corner area are assumed to behave as a classical Euler-Bernoulli beam (i.e., without shear deformations), with a cross-section identical with the rounded corner and with a reference line defined at the theoretical corner line (i.e., intersection of the planes defined by the wider flat plates). The approach is illustrated in Fig. 7.

Mathematically, we are doing a DOF reduction by using the equation as follows:

$\mathbf{d}^{\text {round }}=\mathbf{R}^{\mathbf{c}} \mathbf{d}^{\text {sharp }}$

where $\mathbf{d}^{\text {round }}$ is the displacement vector for the model with rounded corners, $\mathbf{d}^{\text {sharp }}$ is the displacement vector for the model with sharp corners, and $\mathbf{R}^{\mathbf{c}}$ is a constraint matrix for the rounded corners.

As soon as the displacement DOF correspond to that of the sharp-corner model, the "classical" modal decomposition can be performed. Thus, displacements can further be constrained into an arbitrary M mode, by applying Eq. (9) then (12), as follows:

$\mathbf{d}^{\text {round }}=\mathbf{R}^{\mathbf{c}} \mathbf{R}_{\mathrm{M}} \mathbf{d}_{\mathrm{M}}^{\text {sharp }}$

where the matrix $\mathbf{R}^{\mathrm{c}} \mathbf{R}_{\mathrm{M}}$ contains the (modal) displacements of the sharp-corner model that satisfy the mechanical criteria of mode $\mathrm{M}$. 
When, for example, the modal constraints are applied in linear buckling analyses, the reduced elastic and geometric stiffness matrices need to be used in solving the generalized eigen-value problem of Eq. (6), which will take the form as follows:

$$
\mathbf{R}_{\mathrm{M}}{ }^{\mathrm{T}} \mathbf{R}^{\mathrm{c} T} \mathbf{K}_{\mathrm{e}} \mathbf{R}^{\mathrm{c}} \mathbf{R}_{\mathrm{M}} \Phi_{\mathrm{M}}-\Lambda_{\mathrm{M}} \mathbf{R}_{\mathrm{M}}{ }^{\mathrm{T}} \mathbf{R}^{\mathrm{c} \mathrm{T}} \mathbf{K}_{\mathrm{g}} \mathbf{R}^{\mathrm{c}} \mathbf{R}_{\mathrm{M}} \Phi_{\mathrm{M}}=\mathbf{0}
$$

It is to underline that in the above equation $\mathbf{K}_{\mathrm{e}}$ and $\mathbf{K}_{\mathrm{g}}$ stiffness matrices are defined in the rounded-corner model, therefore the effect of rounded corners is directly included in the above solution.

\subsection{Derivation of constraint matrix for the rigid corner}

First, let us consider one single corner element. It is reasonable to assume that the rounded corner is a circular arc, therefore, the cross-section of the corner element is symmetric. A local coordinate system is defined, so that the axis of symmetry is the z-axis, as shown in Fig. 8.

The corner element is modelled by narrow strips. If the corner element behaves as a thin-walled beam-column member (i.e., without cross-section distortion), the displacement of the cross-section of corner element can be expressed by 4 displacement parameters: 2 transverse translations $u_{c 0}$ and $w_{c 0}$, a longitudinal translation $v_{c 0}$, and a twisting rotation $\vartheta_{c 0}$. These displacement parameters must be assigned to some reference point; in our case a convenient reference point is the origin of the local

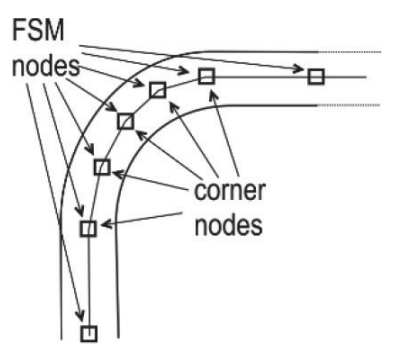

a) FSM model with rounded corner

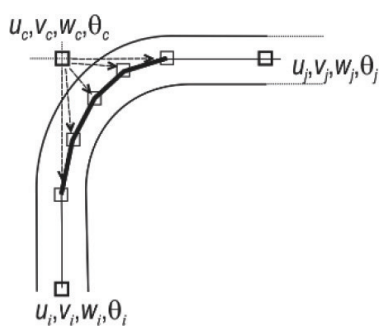

c) effective DOF of the roundedcorner model

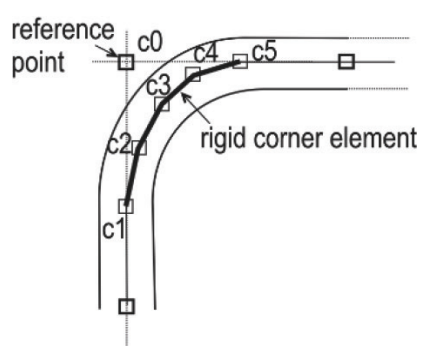

b) rigid corner element

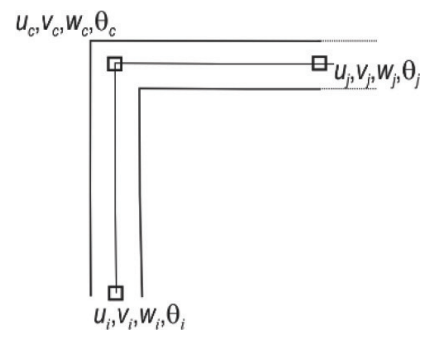

d) DOF of a similar sharp-corner model
Fig. 7 Illustration of the rigid-corner approach coordinate system. By using the 4 displacement parameters the displacements of any cross-section point, including the nodal points of the finite strip model, can unambiguously defined, as illustrated in Fig. 8, by using the following equations:

$$
\begin{aligned}
& u_{c}(x, y, z)=\left(u_{c 0}+\vartheta_{c 0} z\right) \sin \frac{m \pi y}{a} \\
& v_{c}(x, y, z)=\left[v_{c 0}-u_{c 0} \frac{m \pi}{a} x-w_{c 0} \frac{m \pi}{a} z+\vartheta_{c 0} \frac{m \pi}{a}\left(\omega-z_{S C} x\right)\right] \cos \frac{m \pi y}{a} \\
& w_{c}(x, y, z)=\left(w_{c 0}-\vartheta_{c 0} x\right) \sin \frac{m \pi y}{a}
\end{aligned}
$$

$\vartheta_{c}(x, y, z)=\vartheta_{c 0} \sin \frac{m \pi y}{a}$

where $\omega$ is the sectoral coordinate (calculated for the shear center), and $z_{S C}$ is the position of the shear center (which is necessarily located along the z-axis, due to the symmetry of the arc-shaped cross-section).

Thus, the FSM displacement vector for the corner nodes can be expressed as:

$\mathbf{d}_{c}=\mathbf{R}^{c \text {,local }} \mathbf{d}_{c 0}$

where $\mathbf{d}_{c}$ vector contains the nodal displacements of the corner nodes at a given rounded corner, $\mathbf{d}_{c \mathbf{0}}$ contains the nodal displacements of the reference node of the given corner, as follows:

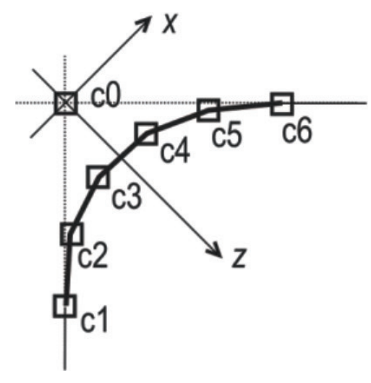

a)

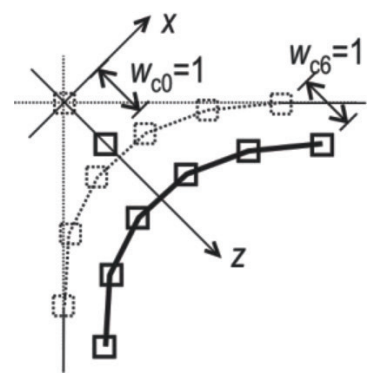

c)

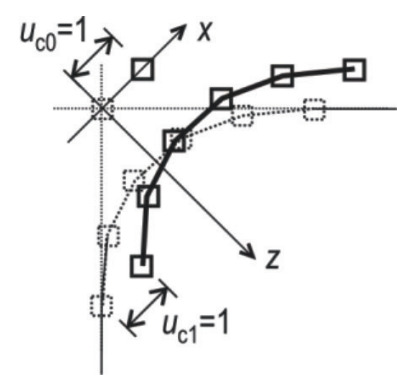

b)

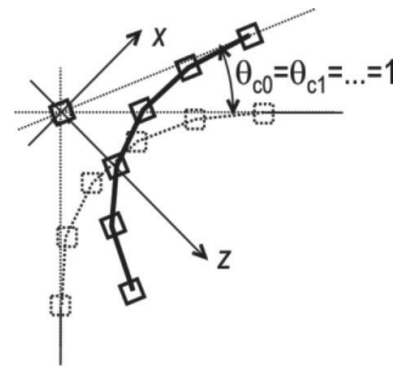

d)
Fig. 8 Corner element: local coordinate system, unit displacements 
$\mathbf{d}_{c}=\left[\begin{array}{c}u_{c 1} \\ v_{c 1} \\ w_{c 1} \\ \vartheta_{c 1} \\ u_{c 2} \\ v_{c 2} \\ w_{c 2} \\ \vartheta_{c 2} \\ \vdots\end{array}\right] \quad \mathbf{d}_{c 0}=\left[\begin{array}{c}u_{c 0} \\ v_{c 0} \\ w_{c 0} \\ \vartheta_{c 0}\end{array}\right]$

$\mathbf{R}^{\mathbf{c}, \text { local }}$ is the constraint matrix for the given rounded corner. Obviously, $\mathbf{R}^{\text {clocal }}$ has 4 columns, and 4 times as many rows as the number of nodes in the rounded corner.

$\mathbf{R}^{\mathbf{c}, \text { local }}=\left[\begin{array}{cccc}1 & 0 & 0 & z_{1} \\ -\frac{m \pi}{a} x_{1} & 1 & -\frac{m \pi}{a} z_{1} & \frac{m \pi}{a}\left(\omega_{1}-z_{S C} x_{1}\right) \\ 0 & 0 & 1 & -x_{1} \\ 0 & 0 & 0 & 1 \\ 1 & 0 & 0 & z_{2} \\ -\frac{m \pi}{a} x_{2} & 1 & -\frac{m \pi}{a} z_{2} & \frac{m \pi}{a}\left(\omega_{2}-z_{S C} x_{2}\right) \\ 0 & 0 & 1 & -x_{2} \\ 0 & 0 & 0 & 1 \\ \vdots & \vdots & \vdots & \vdots\end{array}\right]$

From the local $\mathbf{R}^{\mathbf{c}, \text { local }}$ matrices the global $\mathbf{R}^{\mathbf{c}}$ matrix can be compiled after appropriate rotation of the local $x-z$ to coincide with the global $X-Z$ of the member.

\subsection{Illustrative examples}

To illustrate and study the behavior of the rigid-corner approach, the same three examples are considered that have already been discussed in Section 2.2. The critical stresses for these three cases are calculated in various options. As far as modelling of the corner is concerned, 3 options are considered: sharp-corner, rounded-corner, and the newly introduced rigid-corner. From constraining point of view, 2 options are considered: with and without applying modal constraints. This altogether means 6 calculation options.

As it is shown in Section 2.2, if the modal constraints are applied on models with rounded corners, the calculation can technically be completed, but the results are not acceptable, therefore, thiskind of calculation is notappliedhere.However, certain kind of pure-mode critical stresses for rounded corner models are still provided here, by applying an estimation. The estimation, which is an extrapolation, is based

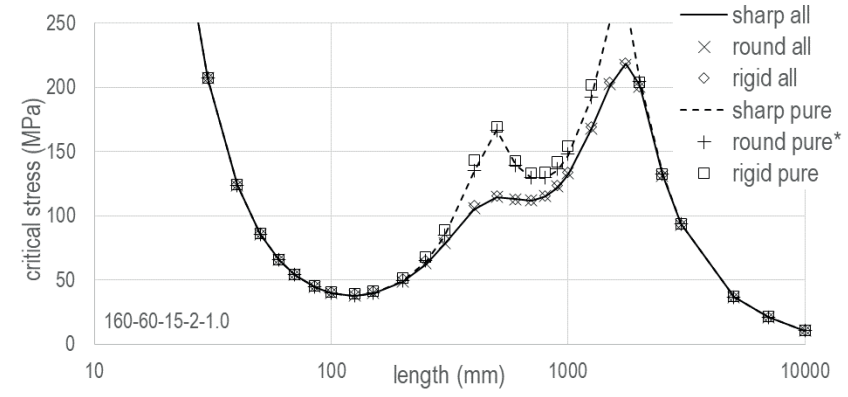

Fig. 9 Signature curves in 6 options, 160-60-15-2-1.0

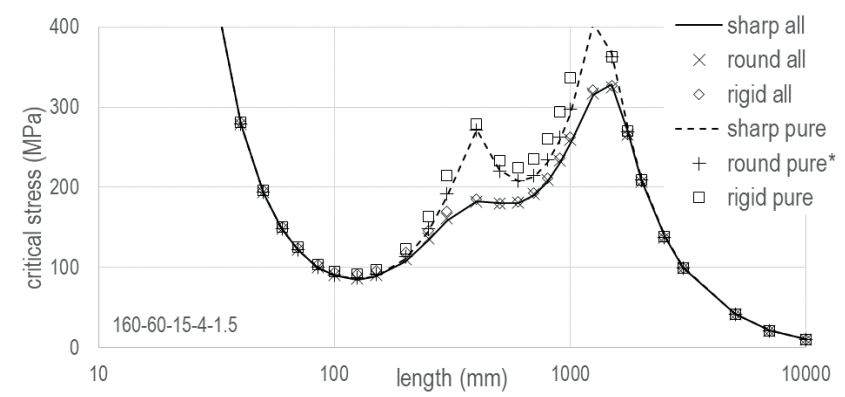

Fig. 10 Signature curves in 6 options, 160-60-15-4-1.5

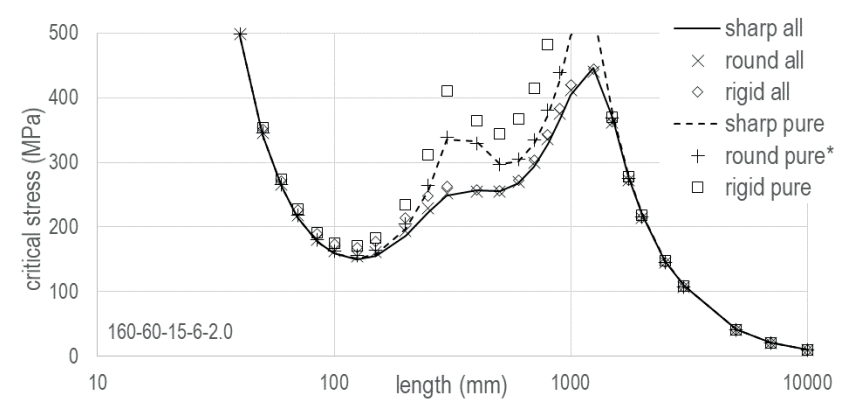

Fig. 11 Signature curves in 6 options, 160-60-15-6-2.0

on the assumption that the effect of mode coupling in the sharp-corner and rounded-corner models are approximately the same. Since the effect of mode coupling (i.e. the difference between the pure-mode and all-mode critical values) can easily be calculated for the sharp-corner models, and the all-mode critical values can also readily be calculated for the rounded-corner models, the pure-mode critical values for the rounded-corner models can be estimated. Practically, the extrapolated pure-mode critical value for rounded-corner cases is calculated as follows: (a) the ratio of the pure-mode and all-mode critical value is calculated for a given length from the sharp-corner model results, (b) the pure-mode critical value of the rounded-corner model for the given length is estimated by multiplying the allmode value of the rounded-corner model by the above ratio. Since at a given length various pure-mode solutions exist, the simple rule is that the above ratio is calculated by 

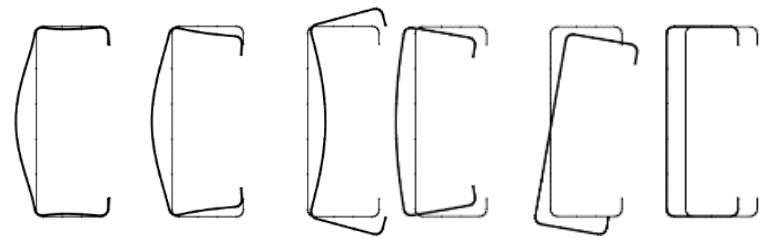

$125 \mathrm{~mm} 300 \mathrm{~mm} 500 \mathrm{~mm} 1000 \mathrm{~mm} 2500 \mathrm{~mm} 10000 \mathrm{~mm}$ a) all-mode calculations

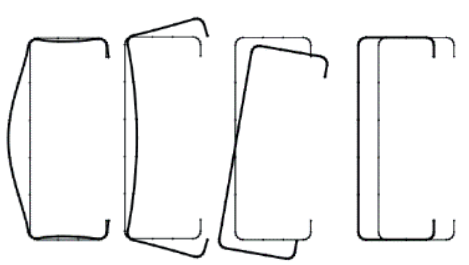

$125 \mathrm{~mm} 500 \mathrm{~mm} 2500 \mathrm{~mm} 10000 \mathrm{~mm}$ b) pure-mode calculations

Fig. 12 Sample buckled cross-section shapes obtained by rigid-corner approach.

using that pure-mode value that is the most characterizing for the given length (i.e., the critical value of which is the smallest among the pure-mode solutions).

In order to distinguish between the regular constrained calculation and the above-described extrapolation, the latter case will be marked as "pure*". (It is to note that the same calculation has been applied in [17] for estimating the pure-mode critical load of members with rounded corners.)

In Figs. 9-11 the signature curves are plotted in all the 6 options for the selected 3 cases. It is to note that - in order to make the plots clear - the envelop curves are plotted for the pure-mode calculations. Samples of buckled cross-sections shapes are shown in Fig. 12.

Numerical values are provided in Tables $5-7$, for 9 lengths, that is 3 lengths from $\mathrm{G}, \mathrm{D}$, and $\mathrm{L}$ domains, selected as explained in Section 2.2.

The most important observation is that the rigid-corner approach successfully eliminates the major problems of pure-mode calculation on rounded-corner models. More specifically, the following conclusions can be drawn.

If the radius of the rounded corner is small enough, the rigid-corner approach seems to work properly for any length. As soon as the radius is increased, there are larger differences. It is reasonable to assume that the rigid-corner approach overestimates the $\mathrm{L}$ and $\mathrm{D}$ critical values, even though the buckling shapes look appropriate. It is evident from the figures and tables, that the scatter of the results is larger when modal constraints are enforced. It also might be suspected that the performance of the rigid-corner approach is better at those lengths where the buckling behavior is less affected by the coupling of various modes.
Table 5 Comparison of critical stresses calculated in 6 options, 160-60$15-2-1.0$

\begin{tabular}{lcccccc}
\hline length & $\begin{array}{c}\text { sharp } \\
\text { corner } \\
\text { all } \\
\text { mode }\end{array}$ & $\begin{array}{c}\text { rounded } \\
\text { corner } \\
\text { all } \\
\text { mode }\end{array}$ & $\begin{array}{c}\text { rigid } \\
\text { corner } \\
\text { all } \\
\text { mode }\end{array}$ & $\begin{array}{c}\text { sharp } \\
\text { corner } \\
\text { pure } \\
\text { mode }\end{array}$ & $\begin{array}{c}\text { rounded } \\
\text { corner } \\
\text { pure* } \\
\text { mode }\end{array}$ & $\begin{array}{c}\text { rigid } \\
\text { corner } \\
\text { pure } \\
\text { mode }\end{array}$ \\
\hline 10 & 1741 & 1741 & 1728 & 1741 & 1741 & 1728 \\
125 & 37.79 & 38.03 & 39.05 & 37.87 & 38.11 & 39.13 \\
400 & 105.2 & 105.7 & 108.3 & 134.5 & 135.1 & 143.6 \\
500 & 114.8 & 114.7 & 115.5 & 167.0 & 166.8 & 168.9 \\
800 & 115.1 & 115.5 & 115.8 & 129.4 & 129.9 & 134.2 \\
1500 & 201.7 & 202.7 & 204.1 & 252.0 & 253.2 & 268.3 \\
1750 & 218.5 & 217.9 & 218.8 & 266.8 & 266.0 & 265.1 \\
3000 & 93.72 & 93.15 & 93.18 & 94.13 & 93.55 & 93.59 \\
10000 & 10.55 & 10.42 & 10.42 & 10.56 & 10.42 & 10.42 \\
\hline
\end{tabular}

Table 6 Comparison of critical stresses calculated in 6 options, 160-60$15-4-1.5$

\begin{tabular}{lcccccc}
\hline length & $\begin{array}{c}\text { sharp } \\
\text { corner } \\
\text { all } \\
\text { mode }\end{array}$ & $\begin{array}{c}\text { rounded } \\
\text { corner } \\
\text { all } \\
\text { mode }\end{array}$ & $\begin{array}{c}\text { rigid } \\
\text { corner } \\
\text { all } \\
\text { mode }\end{array}$ & $\begin{array}{c}\text { sharp } \\
\text { corner } \\
\text { pure } \\
\text { mode }\end{array}$ & $\begin{array}{c}\text { rounded } \\
\text { corner } \\
\text { pure* } \\
\text { mode }\end{array}$ & $\begin{array}{c}\text { rigid } \\
\text { corner } \\
\text { pure } \\
\text { mode }\end{array}$ \\
\hline$(\mathrm{mm})$ & $(\mathrm{MPa})$ & $(\mathrm{MPa})$ & $(\mathrm{MPa})$ & $(\mathrm{MPa})$ & $(\mathrm{MPa})$ & $(\mathrm{MPa})$ \\
\hline 10 & 3918 & 3919 & 3850 & 3918 & 3919 & 3851 \\
125 & 84.79 & 86.26 & 91.00 & 85.20 & 86.68 & 91.64 \\
300 & 158.7 & 161.2 & 170.2 & 188.4 & 191.4 & 214.1 \\
400 & 182.6 & 182.1 & 185.0 & 271.5 & 270.8 & 278.9 \\
600 & 180.6 & 180.8 & 181.3 & 207.2 & 207.5 & 223.9 \\
1250 & 315.2 & 317.2 & 321.2 & 404.8 & 407.4 & 473.0 \\
1500 & 328.5 & 324.7 & 326.8 & 367.4 & 363.1 & 362.8 \\
3000 & 100.1 & 98.80 & 98.82 & 100.3 & 99.05 & 99.56 \\
10000 & 10.56 & 10.27 & 10.27 & 10.56 & 10.28 & 10.28 \\
\hline
\end{tabular}

Table 7 Comparison of critical stresses calculated in 6 options, 160-60$15-6-2.0$

\begin{tabular}{lcccccc}
\hline length & $\begin{array}{c}\text { sharp } \\
\text { corner } \\
\text { all } \\
\text { mode }\end{array}$ & $\begin{array}{c}\text { rounded } \\
\text { corner } \\
\text { all }\end{array}$ & $\begin{array}{c}\text { rigid } \\
\text { corner } \\
\text { all } \\
\text { mode }\end{array}$ & $\begin{array}{c}\text { sharp } \\
\text { corner } \\
\text { pure } \\
\text { mode }\end{array}$ & $\begin{array}{c}\text { rounded } \\
\text { corner } \\
\text { pure* } \\
\text { mode }\end{array}$ & $\begin{array}{c}\text { rigid } \\
\text { corner } \\
\text { pure } \\
\text { mode }\end{array}$ \\
\hline$(\mathrm{mm})$ & $(\mathrm{MPa})$ & $(\mathrm{MPa})$ & $(\mathrm{MPa})$ & $(\mathrm{MPa})$ & $(\mathrm{MPa})$ & $(\mathrm{MPa})$ \\
\hline 10 & 6965 & 6968 & 6752 & 6965 & 6969 & 6755 \\
125 & 150.2 & 155.1 & 168.3 & 151.5 & 156.5 & 171.5 \\
300 & 249.0 & 251.5 & 263.5 & 335.0 & 338.4 & 409.9 \\
400 & 257.4 & 255.1 & 256.9 & 332.4 & 329.4 & 364.6 \\
500 & 255.3 & 254.8 & 255.7 & 297.0 & 296.4 & 344.5 \\
1000 & 404.9 & 411.7 & 419.7 & 495.8 & 504.0 & 659.8 \\
1250 & 446.0 & 440.0 & 444.8 & 532.5 & 525.4 & 523.1 \\
2500 & 147.7 & 144.7 & 144.7 & 148.2 & 145.2 & 147.7 \\
10000 & 10.558 & 10.11 & 10.11 & 10.56 & 10.11 & 10.11 \\
\hline
\end{tabular}




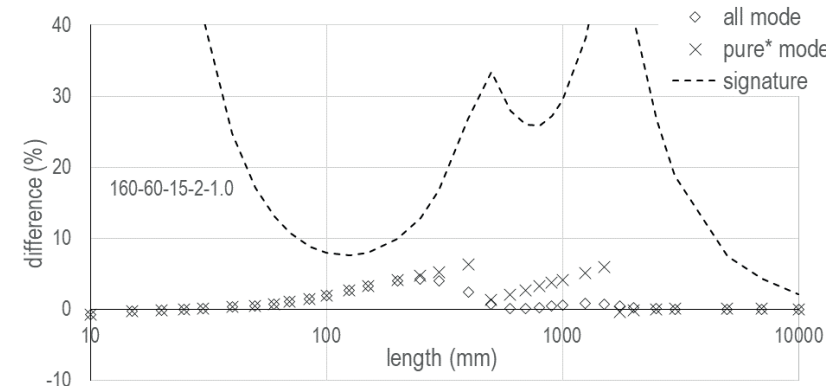

Fig. 13 Differences between critical load results of rigid-corner and rounded-corner calculations, 160-60-15-2-1.0.

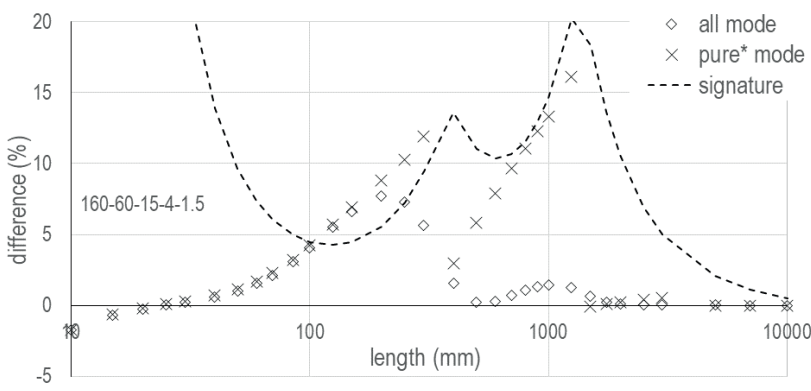

Fig. 14 Differences between critical load results of rigid-corner and rounded-corner calculations, 160-60-15-4-1.5

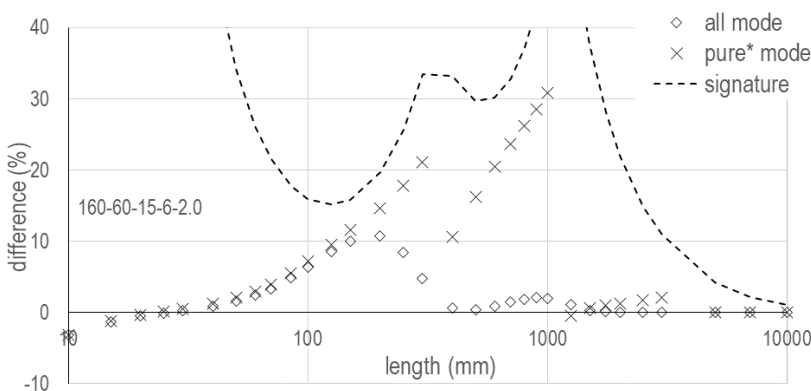

Fig. 15 Differences between critical load results of rigid-corner and rounded-corner calculations, 160-60-15-6-2.0.

In order to have an even closer look at the performance of the rigid-corner approach, the differences between critical values delivered by the rigid-corner and rounded-corner models are determined. The "difference" is interpreted as: ("rigid" - "rounded")/"rounded", expressed in percentages. Positive difference therefore means that the critical value from the rigid-corner model is larger than that from the rounded-corner model. The differences are calculated for both the all-mode and pure-mode solutions, and presented in Figs. 13-15. To be able to see the type of buckling at the various lengths, a signature curve for the given cross-section is also shown in the figures.

If the difference calculated for all-mode solutions is non-zero, this is the error of the rigid-corner model, since within the realm of linear buckling analysis the all-mode FSM solution can be regarded as precise. As the figures show, non-negligible difference in all-mode solutions exists in the $\mathrm{L}$ domain only. The maximal error reaches $5-10 \%$, and the error seems to be increasing with the corner radius. The examples suggest that the maximal error takes place at a buckling length somewhat larger than the $\mathrm{L}$ minimum. The physical explanation of the overestimation must be the fact that the corner region does not remain undeformed in the reality, hence fully rigid corner regions introduce an artificial stiffness increase into the model.

By looking at the pure-mode results, it is to keep in mind that no theoretical solution is known for the exact pure-mode L or D critical load in case of a cross-section with rounded corners. Thus, if the calculated difference is non-zero, this is not necessarily due to the error of one or the other calculation. Even so, if the assumptions from which the estimated pure-mode critical values are derived are realistic, there is reason to think that the above-calculated difference should not be too large. As Figs. 13-15 prove, the differences can be fairly large. Even in the case of small corner radius the difference is up to $7 \%$, but for large corner radii the difference can be as large as 30\%. If the differences are taken at the $\mathrm{L}$ and $\mathrm{D}$ minimums only, the difference values are smaller, but still significant: $5-10 \%$ at the $\mathrm{L}$ minimum, while $5-25 \%$ at the $\mathrm{D}$ minimum. It is also to observe that the rigid-corner approach always lead to larger critical values (at least for any realistic buckling length).

Though there is no solid theoretical basis to judge the correctness of the pure-mode critical values of the rigid-corner approach, it most probably overestimates the pure $\mathrm{L}$ and pure $\mathrm{D}$ critical values of sections with rounded corners. It is observable, that the performance of the rigid-corner approach is dependent on parameters of the problem, especially on the geometrical proportions of the cross-section. Therefore, a large-scale parametric study is completed (as summarized in the next Section) to get information on how the cross-section dimensions influence the results of the rigid-corner model in linear buckling calculations.

\section{Parametric study by using cFSM with rigid corner elements}

\subsection{The completed study}

A parametric study is performed to study the performance of the rigid-corner approach. Simple lipped channel members are analyzed, but with considering a wide range of cross-section geometries, including some unusual geometries, too. 
The considered sections depths are: 80, 120, 160 and 200 $\mathrm{mm}$. The considered flange widths are: 40,60 and $80 \mathrm{~mm}$. The considered lip lengths are: 10,15 and $20 \mathrm{~mm}$. The considered corner radii are: 2, 4 and $6 \mathrm{~mm}$. (All these dimensions are for the middle-line of the cross-section.) The considered thicknesses are: 1.0, 1.5 and $2.0 \mathrm{~mm}$. Hence, the number of considered cross-section geometries is 324 .

A very wide buckling length range is applied, from 1 $\mathrm{mm}$ to $50000 \mathrm{~mm}$, but in the evaluation only the $10-10000$ $\mathrm{mm}$ range is considered (which still wider than the lengths of real practical relevance).

The following discretization is applied for the flat parts of the cross-section: 4 intermediate nodes in the web, and 2 intermediate nodes in each flange (while no intermediate nodes in the lips). This discretization is surely enough to show the tendencies, even if some critical load values might contain a few percent of inaccuracy. When the rounded corners are directly modelled in the finite strip calculation, each rounded corner is approximated by 5 narrow strips. Altogether, therefore, the sharp-corner and rounded-corner models contain 14 and 30 nodes, respectively. (It is to note that a small study has been performed to check the effect of the approximation of the rounded regions, i.e., to check how many strips are to be employed to model the rounded corners. It was concluded that the applicability of the rigid corner element is not affected by the number of strips in the corner regions. The numerical results are affected, but it was also concluded that 4-5 strips are always enough.)

The material is steel, with Young's modulus of $210 \mathrm{GPa}$, but with zero Poisson's ratio. The zero Poisson's ratio is applied in order to avoid the artificial stiffness increasing in $\mathrm{G}$ and $\mathrm{D}$ modes in pure-mode calculations, as discussed in [25-26]. (It is to note, nevertheless, that since here the focus is on studying the performance of the rigid-corner model in comparison with other approaches, the enforcement of zero Poisson's ratio is not crucially important, and it is reasonable to think that it has negligible effect on the conclusions.)

The CUFSM software is employed for the calculations [24]. The critical loads are calculated in 5 options: all-mode and pure-mode with sharp-corner model, allmode and pure-mode with rigid-corner, and all-mode with rounded-corner model. Pure-mode solutions for the rounded-corner model are also determined, not directly by FSM, but by estimation from the all-mode solutions, as discussed previously, in Section 3.3.

\subsection{Evaluation of the results}

The performance of the rigid-corner approach is evaluated by comparing the results from rigid-corner approach to those from rounded-corner calculations. Similarly as in Section 3.3, the difference of the critical loads are calculated, where "difference" is interpreted as: ("rigid" "rounded")/"rounded". Positive difference therefore means that the critical value from the rigid-corner model is larger than that from the rounded-corner model. These differences are studied, as presented next.

\subsubsection{Evaluation of all-mode results}

In case of all-mode solutions the deviation of the rigid-corner model from the regular rounded-corner FSM solution can be regarded as error, due to the distortion of the corner regions, which exists (in smaller or larger extent) in a regular FSM solution, but totally neglected in the rigid-corner approach. The magnitude of the difference, i.e., the error, is surely associated with the corner radius, but also affected by the geometry of the member, as detailed as follows.

If $\mathrm{G}$ buckling governs, the difference between the critical loads calculated with the rigid-corner model and with the rounded-corner model is very small independently of the cross-section geometry. The maximum difference found among the considered cases is $0.3 \%$, but in the vast majority of the cases the difference is less than $0.1 \%$, hence negligible.

Larger differences are experienced for short-to-intermediate buckling lengths. Accordingly L and D critical values might inaccurately be predicted, due to the total neglecting of the distortional deformations of the corner regions. The completed parametric study results suggest that the $\mathrm{L}$ critical values are more affected: considering all the cases the average difference is $5.5 \%$ and $1.8 \%$ for $\mathrm{L}$ and $\mathrm{D}$ minimum critical loads, respectively, with maximum differences being $16.7 \%$ and $9.2 \%$, respectively. Thus, it might be concluded that the assumption of totally rigid corner regions leads to an overestimation of $\mathrm{L}$ and $\mathrm{D}$ critical load values, typically by a few percentage, and a maximum of $10-20 \%$.

The error of $\mathrm{L}$ critical value is found to be proportional to the corner radius, inversely proportional to flange width $(b)$, and also influenced by the flange width to web depth ratio $(b / h)$ and thickness $(t)$, too. The largest inaccuracy occurs if the corner radius is large (i.e. $6 \mathrm{~mm}$ ), web flange width is small (i.e., $40 \mathrm{~mm}$ ), and the $b / h$ ratio is around $0.4-0.5$. 
The error of D critical value is found to be proportional to the corner radius, inversely proportional to the depth of the cross-section $(h)$, and also influenced by the flange width to web depth ratio $(b / h)$. The largest inaccuracy occurs if the corner radius is large (i.e. $6 \mathrm{~mm}$ ), web height is small (i.e., $80 \mathrm{~mm}$ ), and the $b / h$ ratio is around 0.7-1.0. This means that large differences mostly belong to unusual geometries.

\subsubsection{Evaluation of pure-mode results}

In case of pure buckling of members with rounded corners, there is no general solution that could be classified as "exact". In case of pure global buckling, however, either some classical thin-walled beam/column theory can reasonably be applied, or the cFSM approach: thin-walled beam theory and cFSM might lead to slightly different global buckling results [25-26], but both approaches can be classified as exact in an engineering sense. Here the results of rigid-corner approach are compared to those of cFSM (i.e., pure-mode solution from rounded-corner model). Since cFSM is exact for pure global deformations, and since all-mode solutions from the rigid-corner calculations are practically exact, too, the experienced deviation of the rigid-corner critical loads for $\mathrm{G}$ buckling can be regarded as the inaccuracy of the modal decomposition of the rigid-corner model. By analyzing the results of the parametric study, it is observed that in case of pure $\mathrm{G}$ buckling the difference is primarily determined by the type of the buckling, i.e., whether it is flexural buckling or flexural-torsional (FT) buckling. In case of flexural buckling the difference is always small, in the vast majority of the cases well below $1 \%$. In case of flexural-torsional buckling the differences are larger, and can reach as much as $10-20 \%$. The difference is determined by the geometry of the cross-section. All these can be seen in Fig.16, where the differences are plotted against a geometric parameter $g_{1}$, which is defined as:

$g_{1}=r^{4} \frac{1}{h b c} \frac{1}{\sqrt{t}}$

where $h$ is the web depth, $b$ is the flange width, $c$ is the lip length, $t$ is the thickness, and $r$ is the radius of the corner.

Accordingly, the largest differences are obtained when the cross-section is relatively small, but the corner radius is large. Hence, though sometimes the difference is $10-20 \%$, these large differences belong to unusual cross-section geometries, while the difference is only a few percentage for more typical geometries.

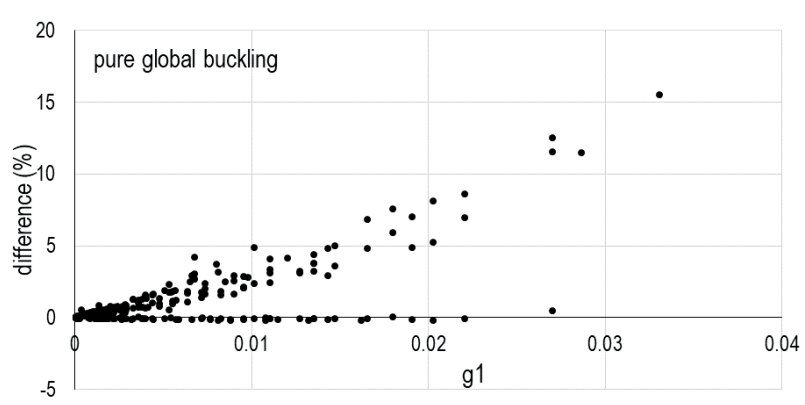

Fig. 16 Differences between rigid-corner and rounded-corner calculations in the parametric study, for pure global buckling

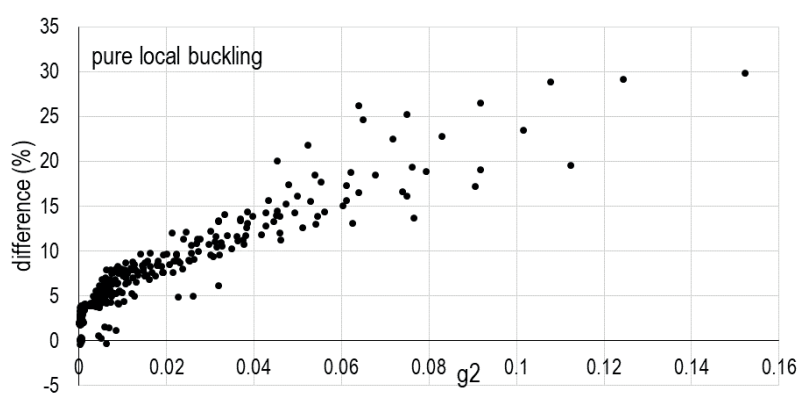

Fig. 17 Differences between rigid-corner and rounded-corner calculations in the parametric study, for pure local buckling

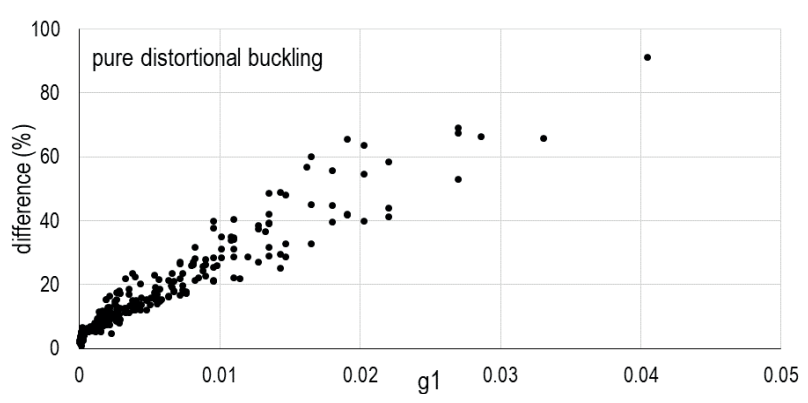

Fig. 18 Differences between rigid-corner and rounded-corner calculations in the parametric study, for pure distortional buckling

In order to have FT buckling as first mode, the channel section flanges should not be too narrow, and the member length should not be too large (since if it is large enough, flexural buckling governs anyway). This also means that larger differences between rigid-corner $\mathrm{G}$ critical load values can be expected if the cross-section shape is more square-like. It is also observable from the detailed analysis of the results that the difference (i.e., the inaccuracy of the pure FT buckling calculation) is decreasing with the increase of the length. It is known, that FT critical value is the sum of two terms, one is associated with Saint-Venant torsion, which is independent of the length, while the other term is associated with warping (i.e., longitudinal translational displacement over a cross-section), which is inversely proportional to the square of the length. All these observations suggest that the inaccuracy of the pure $G$ buckling prediction of the 
rigid-corner model is due to the inaccuracy of the warping distribution when the member is twisted. In fact, small differences exist between the warping from a regular cFSM analysis and that from the rigid-corner analysis.

The behavior of pure L buckling is similar to the allmode local buckling, but slightly different. The error of pure $\mathrm{L}$ critical load is found to be proportional to (in fact: strongly dependent on) the corner radius, inversely proportional to flange width and to the web height, inversely proportional to the thickness, and also influenced by the global shape of the cross-section. A geometric parameter is introduced accordingly, as:

$$
g_{2}=r^{4} \frac{1}{h b t} \frac{1}{\sqrt{c}} \sqrt[4]{\frac{h}{b}}
$$

The differences are plotted in the function of $g_{2}$, as shown in Fig. 17. The differences can be as large as $20-30 \%$. Though the reference value, i.e., the pure critical load estimated from the all-mode solution, is not a precise value, still, the rigid-corner model seems to overestimate pure L critical loads, at least for certain sets of geometrical parameters, especially when the corner radius is large compared to the global dimensions of the cross-section. Certainly, this overestimation is partly due to the total neglecting of the distortion of the corner regions, as it is proved by the all-mode solutions. However, the application of the modal constraints also introduces some inaccuracy, as proved by the pure $\mathrm{G}$ results. These two sources of inaccuracies might be added together. Though sometimes there are large differences, the average difference of the considered cases is not too large, it is equal to approx. $7 \%$.

The difference in pure D critical values is dependent mostly on the same parameters as the FT buckling. This is clear from Fig. 18, where the differences are plotted in the function of the $g_{1}$ parameter (same parameter used in Fig.16). From the actual study the average difference is found to be $15 \%$, but the figure shows that sometimes fairly large differences occur. It seems that the two major sources of inaccuracies (namely: rigid corner regions, and inaccurate modal constraints) might enlarge each other's advert effects. Even though exact solution for pure D buckling of members with rounded corners is not known, the rigid-corner approach surely overestimates the pure D critical load.

\section{Conclusions}

In this paper a technique is proposed and discussed for the modal decomposition of thin-walled structural members with rounded corners. The method is based on the introduction of rigid corner elements, which makes it possible to perform the modal decomposition identically to how it is originally proposed for members with sharp corners. The proposed rigid-corner approach essentially eliminates the major problems caused by the rounded corners in the original constrained finite strip method. A large parametric study has been completed in order to study the performance of the rigid-corner approach in the linear buckling analysis of lipped channel column members. The results of the parametric study show that the rigid-corner approach leads to reasonable pure critical load values for many practical cases, especially if the corner radius of the member is small. Even though there is no exact solution for the pure local or pure distortional buckling of members with rounded corners, there is good reason to conclude that the rigid-corner approach overestimates the critical load in some cases, especially if the corner radius is relatively large. The overestimation is systematic, and is due (at least partially) to the very basic characteristics of the approach, namely: the assumption of totally rigid corners. Though the rigid-corner approach can be regarded as the first modal decomposition technique that works for members with rounded corners, and though it leads to reasonable results for many practical problems, further development of the method is desirable in order to reduce the overestimation of the critical loads.

\section{Acknowledgements}

The presented work was conducted with the financial support of the K119440 project of the Hungarian National Research, Development and Innovation Office.

\section{References}

[1] Schardt, R. "Verallgemeinerte Technische Biegetheorie", 1st. ed., Springer, Berlin, Germany, 1989.

[2] Silvestre, N., Camotim, D., Silva, N. F., "Generalized Beam Theory revisited: from the kinematical assumptions to the deformation mode determination", International Journal of Structural Stability and Dynamics, 11(5), pp. 969-997, 2011.

https://doi.org/10.1142/S0219455411004427

[3] Bebiano, R., Basaglia, C., Camotim, D., Gonçalves, R. "GBT buckling analysis of generally loaded thin-walled members with arbitrary flat-walled cross-sections", Thin-Walled Structures, 123, pp. 11-24, 2018. https://doi.org/10.1016/j.tws.2017.10.045

[4] Ádány, S., Schafer, B. W. "Buckling mode decomposition of single-branched open cross-section members via Finite Strip Method: derivation", Thin-Walled Structures 44(5), pp. 563-584, 2006. https://doi.org/10.1016/j.tws.2006.03.013 
[5] Ádány, S., Schafer, B. W. "Buckling mode decomposition of single-branched open cross-section members via Finite Strip Method: application and examples", Thin-Walled Structures, 44(5), pp. 585-600, 2006.

https://doi.org/10.1016/j.tws.2006.03.014

[6] Ádány, S., Schafer, B. W. "A full modal decomposition of thinwalled, single-branched open cross-section members via the constrained finite strip method", Journal of Constructional Steel Research, 64(1), pp. 12-29, 2008. https://doi.org/10.1016/j.jcsr.2007.04.004

[7] Visy, D., Ádány, S. "Local stiffness matrices for the semi-analytical Finite Strip Method in case of various boundary conditions", Periodica Polytechnica Civil Engineering, 58(3), pp. 187-201, 2014.

https://doi.org/10.3311/PPci.7339

[8] Ádány, S., Schafer, B. W. "Generalized constrained finite strip method for thin-walled members with arbitrary cross-section: Primary modes", Thin-Walled Structures, 84, pp. 150-169, 2014. https://doi.org/10.1016/j.tws.2014.06.001

[9] Ádány, S., Schafer, B. W. "Generalized constrained finite strip method for thin-walled members with arbitrary cross-section: Secondary modes, orthogonality, examples", Thin-Walled Structures, 84, pp. 123-133, 2014. https://doi.org/10.1016/j.tws.2014.06.002

[10] Ádány, S. "Shell element for constrained finite element analysis of thin-walled structural members", Thin-Walled Structures, 105, pp. 135-146, 2016.

https://doi.org/10.1016/j.tws.2016.04.012

[11] Visy, D., Ádány, S. "Local Elastic and Geometric Stiffness Matrices for the Shell Element Applied in cFEM", Periodica Polytechnica Civil Engineering, 61(3), pp. 569-580, 2017. https://doi.org/10.3311/PPci.10111

[12] Ádány, S. "Constrained shell Finite Element Method for thinwalled members, Part 1: constraints for a single band of finite elements", Thin-Walled Structures, 128, pp. 43-55, 2018. https://doi.org/10.1016/j.tws.2017.01.015

[13] Ádány, S., Visy, D., Nagy, R. "Constrained shell Finite Element Method, Part 2: application to linear buckling analysis of thinwalled members", Thin-Walled Structures, 128, pp. 56-70, 2018. https://doi.org/10.1016/j.tws.2017.01.022

[14] Ádány, S., Beregszászi, Z. "Local and Distortional Buckling of Thin-Walled Members: Numerical Study to Compare Conventional and Constrained Finite Strip Method", In: Fifth International Conference on Thin-Walled Structures (ICTWS 2008), Brisbane, Australia, 2008, pp. 1121-1128.

[15] Ádány, S., Beregszászi, Z. "The Effect of Mode Coupling on the Design Buckling Resistance of Cold-Formed Members Calculated via the Direct Strength Method", In: Proceedings of the Eurosteel 2008 Conference (Eurosteel 2008), Graz, Austria, 2008, pp. $117-122$.

[16] Beregszászi, Z., Ádány, S. "The effect of rounded corners of cold-formed steel members in the buckling analysis via the direct strength method", presented at The Twelfth International Conference on Civil, Structural and Environmental Engineering Computing, Funchal, Madeira, Portugal, September 1-4, 2009.
[17] Beregszászi, Z., Ádány, S. "Application of the constrained finite strip method for the buckling design of cold-formed steel members via the direct strength method", Computers and Structures, 89(21-22), pp. 2020-2027, 2011.

https://doi.org/10.1016/j.compstruc.2011.07.003

[18] Zeinoddini, V., Schafer, B. W. "Impact of corner radius on coldformed steel member strength", presented at Proceeding of the 20th International Specialty Conference on Cold-Formed Steel Structures, St. Louis, Missouri, USA, November 3-4, 2010.

[19] Li, Z., Schafer, B. W. "Application of the finite strip method in cold-formed steel member design", Journal of Constructional Steel Research, 66(8-9), pp. 971-980, 2010. https://doi.org/10.1016/j.jcsr.2010.04.001

[20] Ádány, S., Beregszászi, Z. "Constrained finite strip method for thin-walled members with rounded corners", In: Proceedings of Eurosteel 2014, Naples, Italy, 2014, pp. 405-406.

[21] Ádány, S., Beregszászi, Z. "Modal Decomposition for Thin-walled Members with Rounded Corners: an Extension to cFSM by using Elastic Corner Elements", presented at Proceedings of Eighth International Conference on Advances in Steel Structures, Lisbon, Portugal, July 21-24, 2015.

[22] Cheung, Y. K. "The finite strip method in the analysis of elastic plates with two opposite ends simply supported", Proceedings of the Institution of Civil Engineers, 40(1-7), 1968.

[23] Hancock, G. J. "Local, Distortional, and lateral buckling of I-beams", ASCE Journal of structural engineering, 104(11), pp. 1787-1798, 1978.

[24] CUFSM v4.05, Elastic Buckling Analysis of Thin-Walled Members by Finite Strip Analysis, 2012. Available at http://www.ce.jhu.edu/ bschafer/cufsm/index_version4.htm [Accessed: 14.11.2018]

[25] Ádány, S. "Global Buckling of Thin-Walled Columns: Analytical Solutions based on Shell Model", Thin-Walled Structures, Vol 55, pp. 64-75, 2012. https://doi.org/10.1016/j.tws.2012.02.002

[26] Ádány, S., Visy, D. "Global Buckling of Thin-Walled Columns: Numerical Studies", Thin-Walled Structures, 54, pp 82-93, 2012. https://doi.org/10.1016/j.tws.2012.02.001 